\title{
Resorcinol-formaldehyde based carbon nanospheres by electrospraying ${ }^{\#}$
}

\author{
CHANDRA S SHARMA, SANDIP PATIL, SUMAN SAURABH, \\ ASHUTOSH SHARMA* and R VENKATARAGHAVAN ${ }^{\dagger}$ \\ Department of Chemical Engineering and DST Unit on Nanosciences, Indian Institute of Technology, \\ Kanpur 208 016, India \\ ${ }^{\dagger}$ Unilever Research, Hindustan Lever Research Centre, 64, Main Road, Whitefield, Bangalore 560 066, India
}

\begin{abstract}
Carbon nanospheres were synthesized using sol-gel processing of organic and aqueous resorcinol formaldehyde (RF) sols combined with electrospraying technique. RF sol was electrosprayed to form nanodroplets which were collected on a Si wafer. After oven drying at $60^{\circ} \mathrm{C}$ for $12 \mathrm{~h}$, RF nano-droplets were pyrolyzed at $900^{\circ} \mathrm{C}$ in an inert atmosphere to yield the carbon nanospheres. This study reports the optimization of various process parameters including needle diameter, applied electric potential and liquid flow rate in order to get spherical, mono-disperse particles. For the organic RF sol, the optimized parameters, needle diameter $0.241 \mathrm{~mm}$, electric potential, $1.5 \mathrm{kV} / \mathrm{cm}$ and a flow rate of $0.8 \mathrm{ml} / \mathrm{h}$, enabled the synthesis of nearly monodispersed carbon nano-spheres with diameter of $30.2 \pm 7.1 \mathrm{~nm}$. With the same conditions, aqueous RF sol produced irregularly shaped nanoparticles with a smaller mean diameter and much higher variance (17.4 \pm 8.0 $\mathrm{nm}$ ). The surface properties were significantly influenced by the surface morphologies as demonstrated by the water contact angle (WCA) studies. The surface covered with the RF derived carbon nano-spheres was extremely hydrophilic (WCA $10 \cdot 1^{\circ}$ ) as compared to a much weaker hydrophilicity of the RF derived carbon films (WCA $83 \cdot 3^{\circ}$ ). The hydrophilic carbon nanospheres reported here may have potential applications as adsorbents and in controlled drug delivery, biosensors and carbon-based microelectromechanical systems (C-MEMS) including bio-MEMS.
\end{abstract}

Keywords. Carbon nanospheres; electrospraying; sol-gel; pyrolysis; hydrophilic.

\section{Introduction}

Synthesis of spherical carbon particles and other structures of carbon have received a considerable attention in recent years because of their enormous potential in a wide spectrum of applications (Pekala 1989; Alviso et al 1996; Hasegawa et al 2004; Tzeng et al 2004; Lee et al 2005; Shanmugam and Gedanken 2006; CalderonMoreno et al 2007; Macdonald et al 2008; Szot et al 2008; Wang et al 2008; Sharma et al 2009). A variety of carbon particles are being developed in broad ranging applications including adsorbents, drug delivery, anode materials in secondary lithium ion batteries, fuel cells and super-capacitors (Pekala 1989; Alviso et al 1996; Hasegawa et al 2004; Tzeng et al 2004; Lee et al 2005; Shanmugam and Gedanken 2006; Macdonald et al 2008; Szot et al 2008; Wang et al 2008; Sharma et al 2009). There are various approaches reported in the literature to synthesize carbon particles. Some of these include chemical vapour deposition (Wang et al 2006; Calderon-Moreno et al 2007), pyrolysis of hydrocarbon precursors (Lee et al 2005; Wang et al 2008) and sol-gel emulsification (Pekala

\footnotetext{
*Author for correspondence (ashutos@iitk.ac.in) \#Dedicated to Prof. C N R Rao on his 75th birthday
}

1989; Alviso et al 1996; Hasegawa et al 2004; Sharma et al 2009). However, despite the fact that there is a significant literature on the synthesis of spherical carbon particles, reports on preparation of carbon nanospheres are very few (Lee et al 2005; Calderon-Moreno et al 2007; Wang et al 2008)

One of the promising methods to synthesize nanoparticles is electrospraying (Cloupeau and Prunet-Foch 1989, 1990, 1994; Chen et al 1995; Fantini et al 2006; BagheriTar et al 2007; Jaworek 2007; Li et al 2007; Wu and Clark 2007; Jaworek and Sobczyk 2008; Arya et al 2009; Valvo et al 2009). In this technique, liquid flowing out from a nozzle is atomized by applying high electric potential. This allows the elongation of the liquid meniscus to form a jet which finally disrupts into fine charged droplets. Electrospraying offers several advantages over other techniques to form nanoparticles such as synthesis of smaller size particles with a narrow size distribution and high yield (Jaworek 2007; Jaworek and Sobczyk 2008). These nanoparticles may be used as drug delivery carrier as reported by Arya et al (2009) and Fantini et al (2006). While Fantini et al (2006) reported the synthesis of polystyrene micro and nanospheres, Arya et al (2009) electrosprayed chitosan which is a natural polymer widely used in biological applications. Apart from these, tin nanoparticles have also been formed by electrospraying 
for use in lithium ion battery electrodes (Valvo et al 2009). Recently, Li et al (2007) reported the dispersion of silver nanoparticles into electrosprayed sulfonated poly (ether ether ketone) nanostructures to form nano aggregates to be used in catalysis.

In the present work, we study electrospraying of an organic polymer precursor resorcinolformaldehyde (RF) sol which was first introduced by Pekala (1989) to form carbon nanoparticles by emulsification. We also compare the electrospraying characteristics of this organic sol with an aqueous RF sol. RF based carbon gels have been widely used as adsorbents, anode materials in secondary lithium ion batteries, supercapacitors and fuel cells (Pekala 1989; Alviso et al 1996; Hasegawa et al 2004). There are several reports to form carbon microspheres by dispersing RF sol in an organic solvent in the presence of surfactants to form RF microdroplets followed by pyrolysis in inert atmosphere (Hasegawa et al 2004; Sharma et al 2009). However, in this study, we have combined RF sol-gel processing with electrospraying technique to synthesize monodispersed carbon nanospheres. To the best of our knowledge, it is the first report on synthesis of carbon nanospheres by electrospraying method.

Aim of this study is to understand the influence of various process parameters on the size and morphology of the carbon nanospheres prepared by electrospraying followed by pyrolysis. The liquid flow rate, applied electric potential and needle diameter are some of the important parameters which are studied with the objective of obtaining mono-disperse spherical carbon particles. There are various functioning modes of electrospraying (Cloupeau and Prunet-Foch 1989, 1990, 1994; Chen et al 1995). Changes in the operating parameters may alter these functioning modes which control the droplet size and morphology. In addition to this, effect of the RF sol composition is also studied on particle size and morphology. Finally, we demonstrate that highly monodispersed carbon nanospheres may be synthesized by controlling these parameters. These carbon nanospheres may be utilized in a host of scientific and technical applications including biosensors, adsorbents and anode materials in lithium ion secondary batteries to enhance specific capacity of the electrodes.

\section{Experimental}

\subsection{Materials}

Resorcinol (99\% purity), formaldehyde (37\% w/v; stabilized by 11-14 wt.\% methanol), hydrochloric acid (36\%), potassium carbonate (99.0\% purity) and acetone (99.5\%) were purchased from Qualigens Fine Chemicals, India and used as such. While ultra pure milli-Q water was used as a diluent in the preparation of aqueous RF sol, acetone was used for the same purpose in organic RF sol.

\subsection{Preparation of RF sol}

Measured quantities of resorcinol and formaldehyde were added in a beaker and mixed properly for about $15 \mathrm{~min}$ with the help of magnetic stirrer. For organic RF sol, hydrochloric acid used as an acidic catalyst was added to acetone separately. The two solutions were then mixed and stirred continuously for $15 \mathrm{~min}$. In case of aqueous RF sol, potassium carbonate used as a basic catalyst was mixed with water used as a diluent and then stirred continuously for $30 \mathrm{~min}$. The resorcinol to formaldehyde $(\mathrm{R} / \mathrm{F})$ and resorcinol to diluent (R/D) molar ratios were kept constant to be 0.50 and 0.037 , respectively in both the cases. It is to be noted here that water present in the formaldehyde solution is not taken into consideration while calculating the dilution ratio in case of aqueous RF sol. The resorcinol to catalyst molar ratio $(\mathrm{R} / \mathrm{C})$ was 10 and 25 for organic and aqueous RF sol, respectively.

\subsection{Electrospraying set up}

A schematic diagram of the electrospraying set up used in this study is shown in figure 1. It consists of mainly three components: a high voltage d.c. power supply (Gamma high voltage research Inc., USA), a syringe pump (Longer pump, China) mounted with a needle and a grounded collector plate. The flow rate of the polymer solution can be measured and controlled by syringe pump.

\subsection{Synthesis of RF based nanospheres}

RF based nanospheres were synthesized using the electrospraying process. The organic RF sol just before the onset of gelation was placed in a stainless steel needle (nozzle) containing glass syringe. Electrostatic charge was induced on the sol by an external electric field. Increase in the

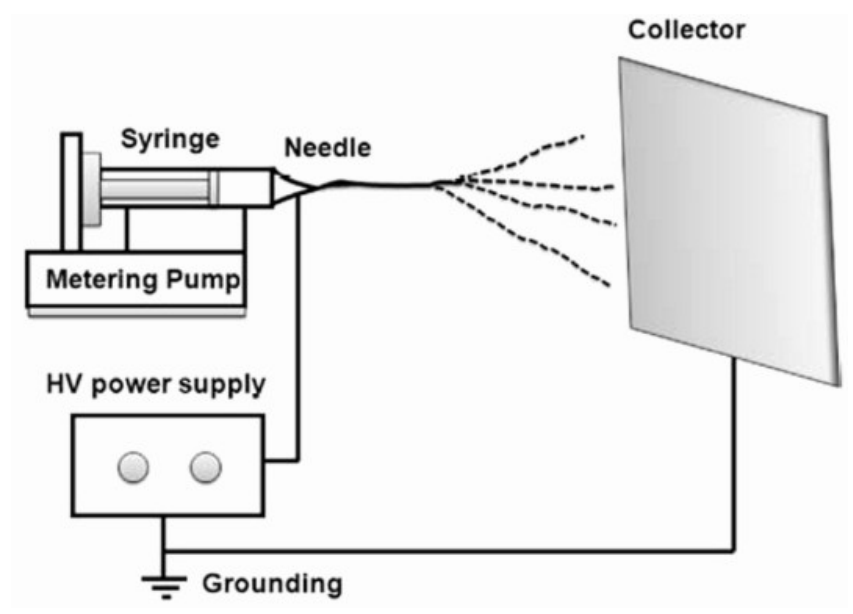

Figure 1. Schematic diagram of electrospraying set-up. 
electric field caused the charges to overcome the surface tension and a straight jet gets ejected from the needle. This jet finally disrupts into the charged droplets while traveling from the tip of the capillary towards the collector screen. The samples were collected on silicon wafer attached with the grounded copper screen. Samples were then dried by heating in oven at $333 \mathrm{~K}$ for $12 \mathrm{~h}$ to ensure complete drying of solvent.

The process parameters were varied one at a time keeping the other variables unaltered to isolate the favourable conditions for electrospraying. The optimization over different parameters was performed in the following order: needle diameter, applied electric potential and flow rate. After some experience with a wider set of values that were obviously outside of the optimal ranges, the following ranges were investigated in detail to control the droplet size, shape and dispersity: (i) use of three different needles of 18, 22 and 26 gauge corresponding to internal diameter of $0.838,0.394$ and $0.241 \mathrm{~mm}$, respectively, (ii) the applied electric potential between needle and collector screen was varied from 1.0 to $2.5 \mathrm{kV} / \mathrm{cm}$ in steps of $0.5 \mathrm{kV}$, and (iii) the $\mathrm{RF}$ sol feed rate was varied in between 0.2 to $2.0 \mathrm{ml} / \mathrm{h}$ in steps of $0.6 \mathrm{ml} / \mathrm{h}$.

Once all these parameters were optimized for the organic RF sol, an aqueous RF sol was also electrosprayed for comparison.

\subsection{Synthesis of carbon nanospheres}

After drying, RF based nanodroplets deposited on a silicon wafer were placed in a quartz boat and heated to $1173 \mathrm{~K}$ under inert nitrogen $\left(\mathrm{N}_{2}\right)$ atmosphere in a tubular, high temperature furnace for carbonization of the RF xerogel nanospheres. Before the pyrolysis process started, nitrogen gas with $0.5 \mathrm{l} / \mathrm{min}$ flow rate was purged for about 15 min into the quartz tube to remove unwanted air or oxygen. The rate of heating was optimized to be at $5.0 \mathrm{~K} / \mathrm{min}$ while the $\mathrm{N}_{2}$ gas flow during heating was kept constant at $0.2 \mathrm{l} / \mathrm{min}$. Once the maximum temperature was reached, it was kept constant for $60 \mathrm{~min}$. The furnace was then cooled to room temperature in about $10 \mathrm{~h}$ to obtain RF derived carbon nanospheres. The inert atmosphere was maintained by purging $\mathrm{N}_{2}$ gas until the furnace attained room temperature.

\subsection{Characterization of carbon nanospheres}

The size, morphology and surface roughness of the RF based carbon nanoparticles were studied using scanning electron microscopy (SEM) (SUPRA 40 VP, Gemini, Zeiss, Germany). These images were then analyzed using Image J software to measure the particle size distribution (PSD). EDAX analysis system (Oxford Instruments Limited, UK) integrated with SEM was used for identifying the elemental composition of these carbon nanospheres. A confocal micro-Raman microscope (CRM 200, WiTec,
Germany with $\lambda=543 \mathrm{~nm}$ ) was used to record the Raman spectra of the pyrolyzed RF based carbon nanospheres to characterize the types of bonds between the elements constituting the material.

Wetting behaviour of surfaces covered with carbon nanoparticles were characterized by measuring equilibrium water contact angle by contact angle goniometer (Rame-Hart Instruments Co., NJ, USA). In most of the measurements, we used $5 \mu \mathrm{l}(\sim 3 \mathrm{~mm}$ spherical drop diameter) water droplets. The functional groups on the surface of carbon nanospheres were characterized by Fourier transform infrared attenuated total reflection spectroscopy (FTIR-ATR) (Bruker Optik, Gmbh, Germany).

\section{Results and discussion}

Micro-Raman spectroscopy was used to confirm that pyrolysis conditions chosen for the electro-sprayed RF nanoparticles indeed yielded carbon nanospheres. A typical Raman spectrum of the pyrolyzed nanoparticles (figure 2) shows two broad peaks centred at about 1338 and $1586 \mathrm{~cm}^{-1}$. These two peaks correspond to well known D and $\mathrm{G}$ bands of graphite, respectively that are associated with the vibrations of $s p^{2}$ carbon atoms with dangling bonds (Wang et al 2003; Sharma et al 2009). The ratio of intensity of the two first-order $\mathrm{D}$ and $\mathrm{G}$ bands as denoted by $I_{\mathrm{D}} / I_{\mathrm{G}}$ is measured to be 1.72 , which indicates a higher fraction of disordered amorphous carbon (Wang et al 2003; Sharma et al 2009).

An EDAX spectrum as shown in figure 3 also confirms the high yield of carbon $(85 \cdot 3 \%)$ after pyrolysis. Some traces of silicon are due to the $\mathrm{Si}$ wafer substrate on which these carbon nanospheres were collected during electrospraying.

\subsection{Optimization of synthesis parameters}

3.1a Effect of needle diameter: The syringe needles with three different gauges 18, 22 and $26 \mathrm{~g}$ (with internal

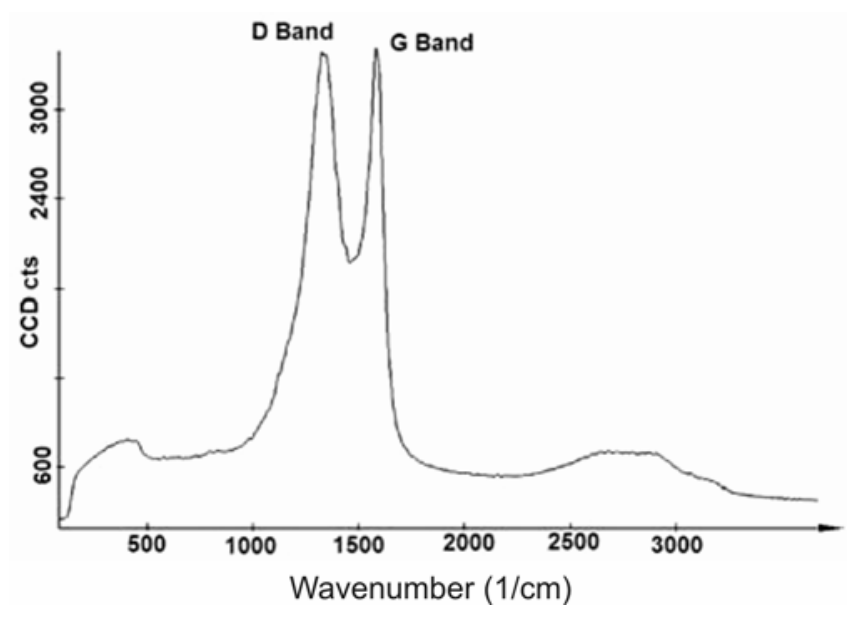

Figure 2. Raman spectrum of RF derived carbon nanospheres. 
diameter of $0.838,0.394$ and $0.241 \mathrm{~mm}$, respectively) were used to study the effect of needle opening on particle size and morphology as shown in figure 4 . Other parameters used were as follows: electric potential, $2 \cdot 0 \mathrm{kV} / \mathrm{cm}$ and flow rate, $0.8 \mathrm{ml} / \mathrm{h}$. At needle gauge of $18 \mathrm{~g}$, we observe a bimodal distribution of RF droplets (figure 4a). The average diameter of primary carbon nanoparticles is $156 \pm 41 \cdot 2 \mathrm{~nm}$, while the secondary droplets comprising a smaller fraction have an average diameter of $32 \cdot 1 \pm 4.7 \mathrm{~nm}$.

The bimodal distribution obtained by a relatively wide syringe appears to be a spindle mode of electrospraying in which droplets of non-uniform size coexist (Cloupeau and Prunet-Foch 1989, 1990, 1994). A wide syringe facilitates faster RF sol flow resulting in large diameter primary drops together with the formation of secondary droplets by fragmentation of larger drops by electrostatic repulsion (Cloupeau and Prunet-Foch 1989, 1990, 1994). Also, higher flow rate promotes greater agglomeration of deposited droplets as shown in figure $4 \mathrm{a}$. When employing a narrower needle of $22 \mathrm{~g}$, flow rate was found to be sufficiently low to form a stable jet which fragmented more regularly into nano-droplets thus decreasing the particle-polydispersity as shown in figures $4 \mathrm{~b}-\mathrm{c}$. Average diameter of carbon nanoparticles for this case was found out to be $74.3 \pm 14.2 \mathrm{~nm}$. Further, the jet using $26 \mathrm{~g}$ needle was even finer than that of $22 \mathrm{~g}$ needle. It resulted in nearly monodispersed carbon nanospheres with an average diameter of $42 \cdot 8 \pm 6 \cdot 3 \mathrm{~nm}$ as shown in figures $4 d-e$.

\begin{tabular}{|lcll|}
\hline Element & $\begin{array}{r}\text { Weight } \\
\%\end{array}$ & $\begin{array}{c}\text { Weight } \% \\
\sigma\end{array}$ & Atomic \% \\
Carbon & 85.259 & 0.391 & 89.336 \\
Oxygen & 11.989 & 0.400 & 9.431 \\
Silicon & 2.751 & 0.048 & 1.233 \\
\hline
\end{tabular}

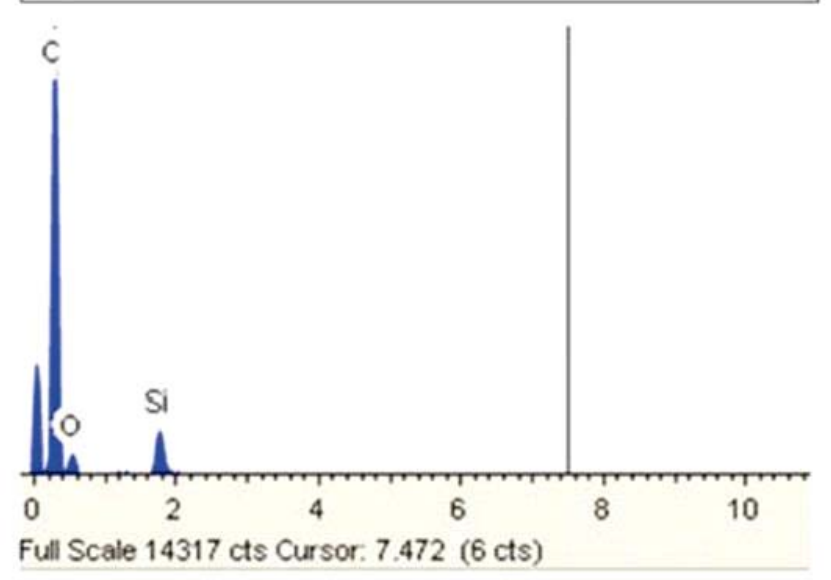

Figure 3. EDAX spectrum of carbon nanospheres.
As particles using needle gauge 26 were smallest and monodispersed in size and also spherical in shape, syringe needle of $26 \mathrm{~g}$ was used for further experiments.

3.1b Effect of applied electric potential: The effect of applied electric potential on average diameter of carbon nanospheres is summarized in figures $5 \mathrm{a}-\mathrm{h}$. The electric potential was applied in the range of 1.0 to $2.5 \mathrm{kV} / \mathrm{cm}$ with increments of $0.5 \mathrm{kV} / \mathrm{cm}$. Volume feed rate of RF sol was fixed at $0.8 \mathrm{ml} / \mathrm{h}$. At $1.0 \mathrm{kV} / \mathrm{cm}$, larger diameter droplets (average diameter 206.8 $\pm 26.9 \mathrm{~nm}$ ) were formed as shown in figures $5 \mathrm{a}-\mathrm{b}$. After an increase in the electric potential to $1.5 \mathrm{kV} / \mathrm{cm}$, there is a significant reduction in the average diameter $(36.9 \pm 8.1 \mathrm{~nm})$ of carbon nanospheres. In these two cases, particles were nearly monodispersed. On increasing the applied electric potential further to $2.0 \mathrm{kV} / \mathrm{cm}$, nanoparticles with a reduced average diameter, but a much wider size distribution of $23 \cdot 1 \pm 16 \cdot 7 \mathrm{~nm}$ were formed as shown in figures $5 \mathrm{e}-\mathrm{f}$. We observed a prominent bimodal distribution of carbon nanoparticles at very high electric potential $(2 \cdot 5 \mathrm{kV} / \mathrm{cm})$. The average diameter of primary carbon nanoparticles in this case was $43.7 \pm 14.9 \mathrm{~nm}$, while the secondary droplets size was $1.4 \pm 4.0 \mathrm{~nm}$.

Effect of applied electric potential may be explained better by various functioning modes reported in literature (Cloupeau and Prunet-Foch 1989, 1990, 1994; Chen et al 1995). At very low electric potential, RF sol flows drop by drop in pulsatile motion that is termed as the dripping mode of electro-spinning (Chen et al 1995). In this mode, the emission of droplets occurs at regular time intervals without the creation of secondary droplets. On increasing the electric potential beyond a critical value, the functioning mode changes to cone-jet with kink instabilities manifesting in irregular emission of droplets (Cloupeau and Prunet-Foch 1989, 1990, 1994). At a sufficiently high potential, a multi-jet mode is observed which causes bi-modal distribution of droplet size. Thus, applied electric potential shows a prominent effect on particles size as discussed above. However, it does not have a significant role in controlling the particle morphology.

Although carbon nanoparticles with the smallest average diameter $(23.1 \pm 16.7 \mathrm{~nm})$ were formed at $2.0 \mathrm{kV} / \mathrm{cm}$, these displayed high polydispersity. Thus, further experiments were performed at $1.5 \mathrm{kV} / \mathrm{cm}$, which resulted in nearly mono-dispersed carbon nano-spheres.

3.1c Effect of volumetric flow rate: $\mathrm{RF}$ sol flow rate was varied between 0.2 and $2.0 \mathrm{ml} / \mathrm{h}$ with increments of $0.6 \mathrm{ml} / \mathrm{h}$ to study its effect on nano-particle formation. As shown in figure $6 \mathrm{a}$, at $0.2 \mathrm{ml} / \mathrm{h}$, average diameter of particles is $17 \cdot 1 \pm 8.8 \mathrm{~nm}$, which increases to $30.2 \pm 7 \cdot 1 \mathrm{~nm}$ at $0.8 \mathrm{ml} / \mathrm{h}$ (figure $6 \mathrm{~b}$ ). In the latter case, carbon nanospheres are nearly monodisperse. This case may be explained by micro-dripping functioning mode observed at low flow rates (Cloupeau and Prunet-Foch 1989, 1990, 

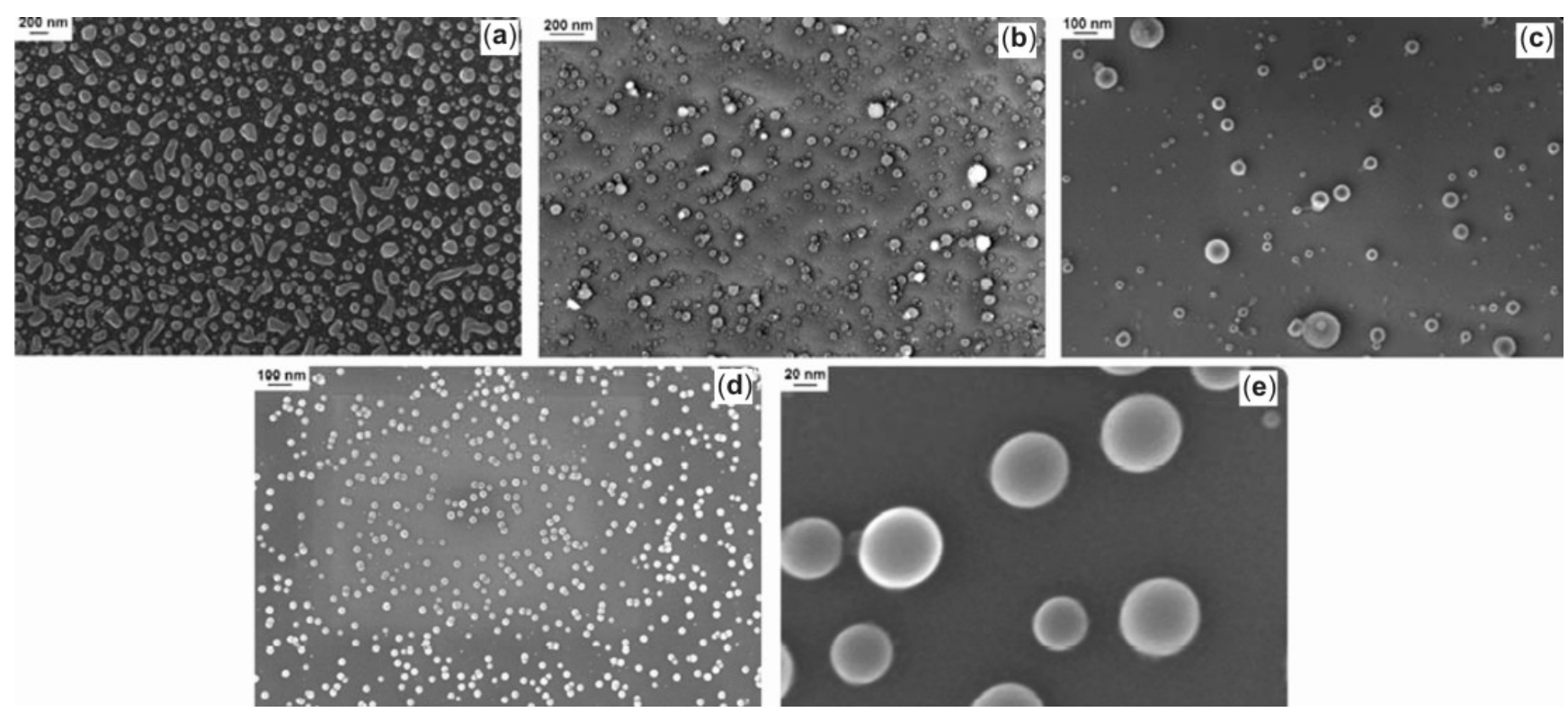

Figure 4. SEM images showing the effect of needle gauge on the size and morphology of carbon nanospheres: needle gauge (a) $18 \mathrm{~g}$; (b) $22 \mathrm{~g}$; (c) magnified view of (b); (d) $26 \mathrm{~g}$; (e) magnified view of (d). Other parameters are electric potential, $2.0 \mathrm{kV} / \mathrm{cm}$ and flow rate, $0.8 \mathrm{ml} / \mathrm{h}$.

1994). In this mode, emission occurs at regular time intervals thus forming uniform size droplets. It may also be noted that size of the droplets is expected to be proportional to the flow rate (Chen et al 1995), which is indeed observed in our experiments on increasing the flow rate to $1.4 \mathrm{ml} / \mathrm{h}$. In this case as shown in figures $6 \mathrm{c}-\mathrm{d}$, average particle diameter of carbon nanospheres was measured to be $88.4 \pm 30 \cdot 1 \mathrm{~nm}$. On further increasing the flow rate to $2.0 \mathrm{ml} / \mathrm{h}$, larger particles with average diameter $212 \pm$ $37.9 \mathrm{~nm}$ are formed which also agglomerate more readily as shown in figure $6 \mathrm{e}$.

Based on the studies presented above, needle diameter, applied electric potential and flow rate of RF sol are found to play a significant role in controlling the average diameter of electrosprayed carbon nanospheres. The following set of parameters, needle gauge, $26 \mathrm{~g}$, applied electric potential, $1.5 \mathrm{kV} / \mathrm{cm}$, at RF sol flow rate, $0.8 \mathrm{ml} / \mathrm{h}$, yield highly monodisperse carbon nanospheres with average diameter, $30 \cdot 2 \pm 7 \cdot 1 \mathrm{~nm}$.

\subsection{Electrospraying of aqueous RF sol}

To examine the effect of RF sol composition, aqueous RF sol was also electrosprayed with the optimized parameters found for the organic diluent based RF sol. The carbon particles derived from electrospraying of an aqueous sol are shown in figure 7 . The average particle diameter in case of aqueous $\mathrm{RF}$ sol reduces to $17.3 \pm 8.2 \mathrm{~nm}$ (figure $7 \mathrm{~b})$ as compared to $30 \cdot 2 \pm 7 \cdot 1 \mathrm{~nm}$ for acetone based $\mathrm{RF}$ sol (figure 7a). However, deformation of particles to nonspherical shapes, as well as their agglomeration, become prominent in this case. The reduction in the average particles size may be because of a higher charge generation and conductivity of the aqueous sol. The droplet diameter has been argued to be inversely proportional to liquid conductivity of the electrosprayed liquid (Chen et al 1995). For liquids with relatively high conductivity (water in this case), the cone-jet mode with a reduction in the droplet diameter makes its appearance at lower flow rates (Cloupeau and Prunet-Foch 1989, 1990, 1994).

\subsection{Wetting behaviour of carbon nanospheres}

An understanding of the wetting behaviour of the carbon nanospheres reported in this work may be useful to find particular applications for these carbon nanospheres. For this, WCA studies were conducted which revealed that surface properties were significantly influenced by the surface morphologies. Thin films of organic RF sol were prepared by spin coating it at $3000 \mathrm{rpm}$ and drying at $60^{\circ} \mathrm{C}$ for $12 \mathrm{~h}$. Smooth carbon films were obtained after pyrolysis at the same conditions as mentioned earlier.

The surface chemistry of these carbon nanospheres was also studied by FTIR in the attenuated total reflection mode to support the contact angle results. Figure 8 shows FTIR-ATR spectra of organic RF sol based carbon nanospheres. The reference database for interpretation of peaks has been taken from FDM reference spectra databases. Presence of strong peaks between 2290 and $2390 \mathrm{~cm}^{-1}$ attributes the presence of stretching vibration of hydroxyl group (-OH group). Moreover, other oxygencontaining functional group such as carbonyl is also evi- 

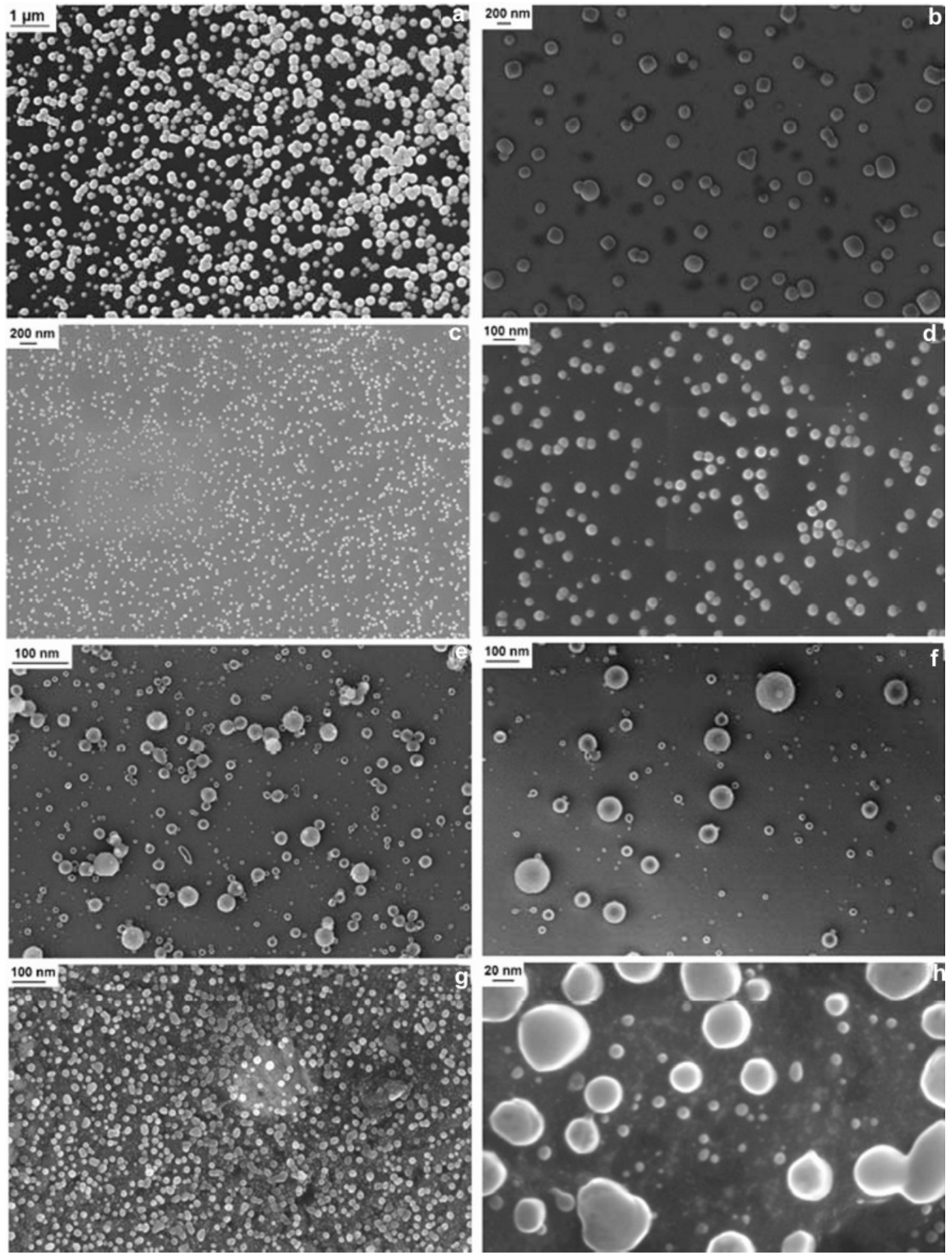

Figure 5. SEM images showing the effect of applied electric potential on the size and morphology of carbon nanospheres: electric potential. a. $1.0 \mathrm{kV} / \mathrm{cm} ;$ c. $1.5 \mathrm{kV} / \mathrm{cm} ;$ e. $2.0 \mathrm{kV} / \mathrm{cm} ;$ g. $2.5 \mathrm{kV} / \mathrm{cm}$. Images $\mathbf{b}, \mathbf{d}, \mathbf{f}$ and $\mathbf{h}$ are magnified view of $\mathbf{a}, \mathbf{c}, \mathbf{e}$ and $\mathbf{g}$, respectively. Other parameters are needle gauge, $26 \mathrm{~g}$ and flow rate, $0 \cdot 8 \mathrm{ml} / \mathrm{h}$.

dent in the spectrum $\left(1647 \mathrm{~cm}^{-1}\right)$. Besides these functional groups, strong peaks at $707 \mathrm{~cm}^{-1}$ and $671 \mathrm{~cm}^{-1}$ can be assigned to out of plane bending of $-\mathrm{OH}$ group and outof-plane deformation vibration of $\mathrm{C}-\mathrm{H}$ presence in $\mathrm{RF}$ gel derived carbon.
Figure 9 summarizes the contact angle measurement studies on RF derived smooth surfaces and on surface covered with nanospheres. The RF derived smooth carbon films show a very weak hydrophilicity (WCA $83.3 \pm 1 \cdot 6^{\circ}$ ) derived from the surface $-\mathrm{OH}$ groups. 

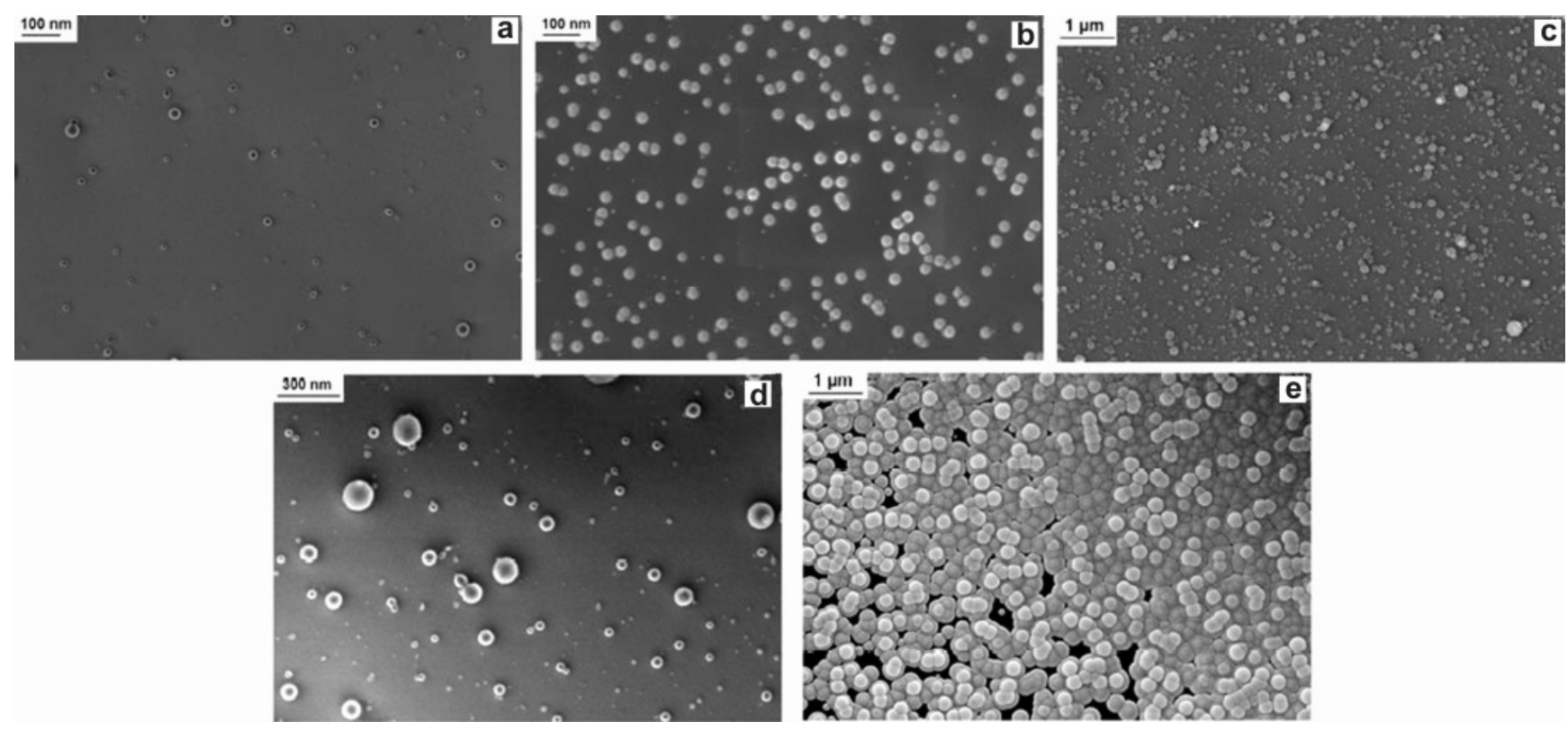

Figure 6. SEM images showing the effect of volumetric flow rate on the size and morphology of carbon nanospheres: flow rate a. $0.2 \mathrm{ml} / \mathrm{h}, \mathbf{b} .0 .8 \mathrm{ml} / \mathrm{h}$, c. $1.4 \mathrm{ml} / \mathrm{h}, \mathbf{d}$. magnified view of c; e. $2.0 \mathrm{ml} / \mathrm{h}$. Other parameters are electric potential, $2.0 \mathrm{kV} / \mathrm{cm}$ and flow rate, $0.8 \mathrm{ml} / \mathrm{h}$.
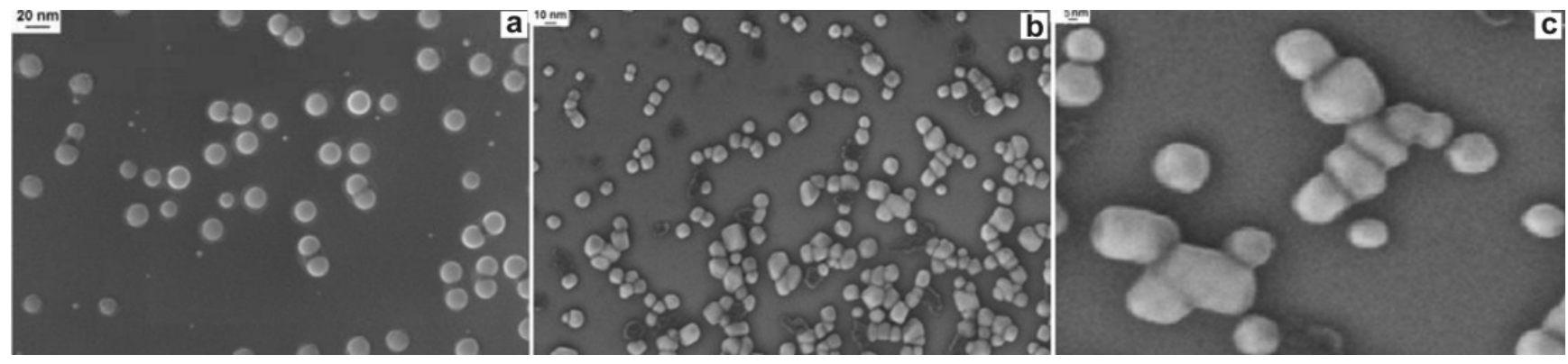

Figure 7. SEM images of carbon nanospheres at optimized parameters (needle gauge $26 \mathrm{~g}$, applied electric potential: $1.5 \mathrm{kV} / \mathrm{cm}$ and flow rate: $0.8 \mathrm{ml} / \mathrm{h}$ ) derived by two different types of RF sol: a. acetone based, $\mathbf{b}$. water based, and $\mathbf{c}$. magnified view of $\mathbf{b}$. Scale bars correspond to 20,10 and $5 \mathrm{~nm}$, respectively in $\mathbf{a}-\mathbf{c}$.

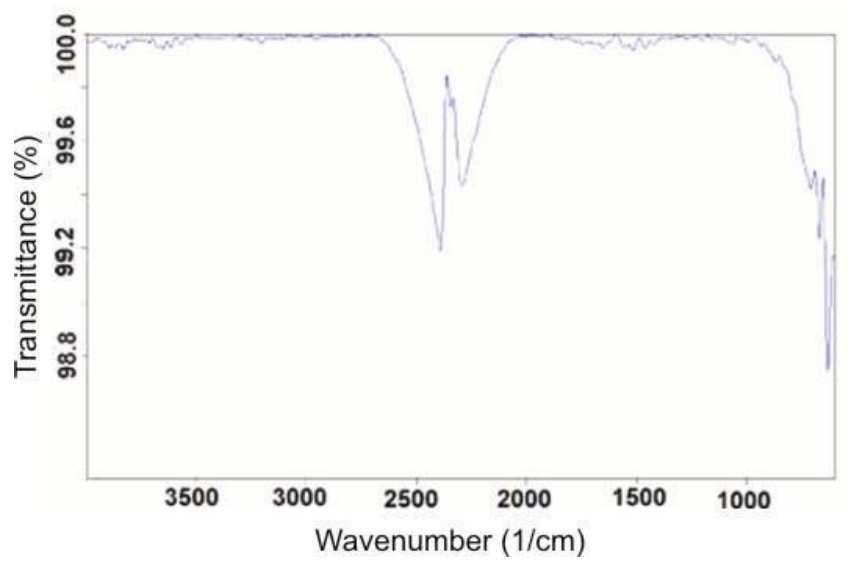

Figure 8. FTIR-ATR spectrum of RF derived carbon nanospheres surface.
Interestingly, the water contact angle on carbon nanosphere surfaces was measured to be $10 \cdot 1 \pm 2 \cdot 8^{\circ}$, which further reduced to $5 \pm 1.8^{\circ}$ after $8 \mathrm{~min}$. This observation shows a very important role of surface roughness and porosity contributed by the nanospheres. By deposition of electrosprayed carbon nanospheres, i.e. by increasing the surface roughness at nano-scale, carbon surface covered with nanospheres approached superhydrophilicity. This phenomenon is theoretically explained by Wenzel (1936) where wettability increases with roughness for a smooth hydrophilic material, as indeed observed in this case.

Surface properties and wettability play an important role in many applications of carbon surfaces (Tzeng et al 2004). Strongly hydrophilic carbon nanosphere surfaces may have applications in biosensors, relative humidity sensing and gas sensing. The carbon nanospheres are also 
potential candidates in applications involving controlled drug delivery and as an electrode material in rechargeable batteries, fuel cells and super-capacitors (Shanmugam and Gedanken 2006; Macdonald et al 2008; Szot et al 2008). Recently, Wang et al (2006) reported the integration of carbon nanostructures with carbon microelectrochemical systems (C-MEMS) to enhance their performance. Similarly, deposition of carbon nanospheres on high aspect ratio carbon posts as shown in figure 10 should greatly increase the external surface area available for intercalation of lithium ions thus increasing the specific capacity of the battery electrode.

\section{Conclusions}

This study establishes electrospraying to be a facile technique for the production of monodisperse carbon nanospheres. Resorcinol-formaldehyde based organic sol could be successfully electrosprayed for the first time to yield RF nanospheres followed by pyrolysis in an inert atmosphere to obtain carbon nanospheres. The size and morphology of these carbon nanoparticles may be manipulated by varying the process parameters such as needle gauge diameter, applied electric potential and flow rate. These parameters are optimized to yield nearly monodispersed carbon nanospheres with average diameter $30 \cdot 2 \pm 7 \cdot 1 \mathrm{~nm}$. Variation in these parameters from the optimized values leads to remarkable changes in the particle size distribution and morphology, which can be explained by different functioning modes of electrospraying. Raman spectroscopy confirmed the amorphous nature of carbon while EDAX analysis also confirmed the higher yield of carbon from resorcinol-formaldehyde based sol. Interesting wettability behaviour is observed with carbon nanoparticles surfaces which show extreme structural hydrophilicity (water contact angle, $\sim 5-10^{\circ}$ ) in comparison to flat RF sol derived carbon films (water contact angle, $\sim 90^{\circ}$ ). The carbon nanospheres synthesized here may have a variety

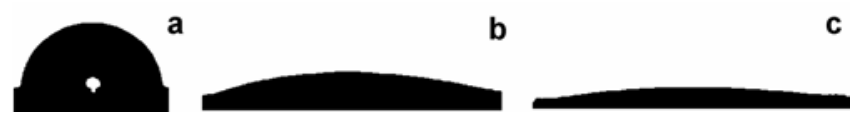

Figure 9. Water contact angles on a. RF sol derived smooth carbon thin film, b. RF sol derived carbon nanospheres film initially and c. RF derived carbon nanospheres film after $8 \mathrm{~min}$.

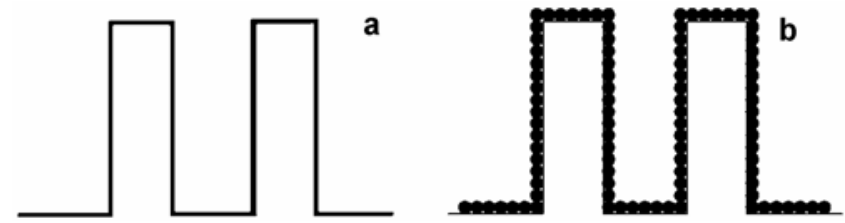

Figure 10. Schematic of a. high aspect ratio carbon posts and b. conformal deposition of carbon nanospheres on high aspect ratio carbon posts. of potential applications in the field of adsorbents, drug delivery, bio-sensors, gas and humidity sensing devices, electrode material for batteries, super-capacitors and fuel cells.

\section{Acknowledgements}

This work is supported by Unilever Research (India), DST Unit on Nanosciences at IIT Kanpur, and by a grant from the DST-IRHPA. Helpful discussions with Marc Madou (UCI) are gratefully acknowledged. It is a pleasure to be a part of the Festschrift for Professor C N R Rao, whose work has been a constant inspiration for us.

\section{References}

Alviso C T, Pekala R W, Gross J, Lu X, Caps R and Fricke J 1996 Mater. Res. Soc. Symp. Proc. 431521

Arya N, Chakraborty S, Dube N and Katti D S 2009 J. Biomed. Mater. Res. Part B: Appl. Biomater. B88 17

Bagheri-Tar F, Sahimi M and Tsotsis T T 2007 Ind. Eng. Chem. Res. 463348

Calderon-Moreno J M, Labarta A, Batlle X, Pradell T, Crespo D and Binh V T 2007 Chem. Phys. Lett. 447295

Chen D -R, Pui D Y H and Kaufman S L 1995 J. Aerosol Sci. 26963

Cloupeau M and Prunet-Foch B 1989 J. Electrostatics 22135

Cloupeau M and Prunet-Foch B 1990 J. Electrostatics 25165

Cloupeau M and Prunet-Foch B 1994 J. Aerosol Sci. 251021

Fantini D, Zanetti M and Costa L 2006 Macromol. Rapid Commun. 272038

Hasegawa T, Mukai S R, Shirato Y and Tamon H 2004 Carbon 422573

Jaworek A 2007 Powder Technol. 17618

Jaworek A and Sobczyk A T 2008 J. Electrostatics 66197

Lee S, Mitani S, Park C W, Yoon S, Korai Y and Mochida I 2005 J. Power Sources 139379

Li X, Hao X and Na H 2007 Mater. Lett. 61421

Macdonald S M, Szot K, Niedziolka J, Marken F and Opallo M 2008 J. Solid State Electrochem. 12287

Pekala R W 1989 J. Mater. Sci. 243221

Shanmugam S and Gedanken A 2006 J. Phys. Chem. B110 2037

Sharma C S, Kulkarni M M, Sharma A and Madou M 2009 Chem. Eng. Sci. 641536

Szot K et al 2008 J. Electroanal. Chem. 623170

Tzeng Y, Huang T S, Chen Y C, Liu C and Liu Y K 2004 New Diamond and Frontier Carbon Tech. 14193

Valvo M, Lafont U, Munao D and Kelder E M 2009 J. Power Sources 189297

Wang C, Zaouk R and Madou M 2006 Carbon 443073

Wang Y, Serrano S and Santiago-Aviles J J 2003 Synth. Metals 138423

Wang Y, Su F, Wood C D, Lee J Y and Zhao X S 2008 Ind. Eng. Chem. Res. 472294

Wenzel R N 1936 Indust. Eng. Chem. 28988

Wu Y and Clark R L 2007 J. Colloid Interf. Sci. 310529 